\title{
Modeling and Performance Optimization of the U-pipe Glass Evacuated Tube Solar Collector
}

\author{
Xiaomeng Chen ${ }^{1}$, Fang Guo ${ }^{1}$, Chunlin Wang ${ }^{2}$, Xudong Yang ${ }^{1}$ \\ ${ }^{1}$ Department of Building Science, Tsinghua University, Beijing 100084, China \\ ${ }^{2}$ Department of Resources, Environment and Architectural Engineering, Chifeng College, Chifeng \\ 024000, China
}

\begin{abstract}
In this study, the heat transfer process of U-pipe glass evacuated tube collector is analysed by one-dimensional method, where a detailed fin model is developed with the effect of temperature difference between two legs of Upipe taken into account. The thermal model is further verified with experimental data from literature, and the computational result matches good with the measurement data. Further, an optimization method is proposed to reduce the thermal resistance caused by air gap between the absorber tube and the aluminium fin. By adding a high emissivity coating on the fin surface, the thermal resistance of air gap per collector length is reduced to 0.18 $(\mathrm{mK}) / \mathrm{W}$ and thermal performance of collector can be $2.6 \%$ higher after optimization. Study finds that the thermal efficiency improvement through this method increases with increase of collector working temperature and solar radiation intensity, which indicates that this method has high optimization potential in intermediate and high temperature application.
\end{abstract}

\section{Introduction}

The increasing problems of $\mathrm{CO}_{2}$ emission and fossil energy shortage have promoted application of renewable energy worldwide. Solar energy, as one of the most comparable clean energy sources, have widely been applicated in power, heating, and cooling process. Solar collectors, which can convert sunlight into useful thermal energy efficiently, have been widely utilized in domestic hot water and space heating sector. At present, different collector types have been developed, among which flat plate and glass evacuated tube collector are the two most commonly used forms. Compared with flat plate collector, glass evacuated tube collector has a better thermal insulation and shows a higher performance operating in cold weather conditions. With continuously dropping price, evacuated tube collectors have been rapidly promoted in solar heating market, including heat pipe evacuated solar collectors and U-pipe glass evacuated tube solar collectors. Heat pipe type has advantages in certain aspects, such as anti-freezing, rapid start-up, resistance to high pressure, but the accumulated incondensable gas in heat pipe can restrict the normal operation and shorten collector service life (He ZN. et al 1997). Compared with heat pipe evacuated tube collector, using U-pipe to extract heating energy can maintain operation with higher stability.
Plenty of researchers have devoted into the study of thermal behaviour of U-pipe glass evacuated tube collector. Kim and Seo (2007) studied four shapes of absorber tubes theoretically and experimentally, and found that a single collector tube with U-pipe inserted in a circular fin has the best performance. However, if the effect of shadow and diffuse irradiation caused by adjacent tubes is taken into account, U-pipe embedded onto a flat fin is considered to be the best configuration. Tian (2007) deduced the calculation equations of the efficiency factor and the heat transfer loss coefficient, and found that the emittance ratio of selective absorbing coating has great influence on the thermal efficiency. Ma (2010) further developed a one-dimension analytical model based on energy balance to investigate the thermal performance of U-pipe evacuated tube collector, his study indicated that the thermal resistance caused by air gap between absorber tube and copper fin hinders the heat transfer process significantly. Gao (2014) proposed a mathematical model which simplified the U-pipe into an equivalent straight pipe and verified this model with experimental data.

Many efforts have been made to achieve a higher collector efficiency. To eliminate thermal resistance caused by air gap, Dirk (2008) proposed a filled-type evacuated tube collector with U-pipe, in which the space between absorber tube and U-pipe is filled with thermal conduction element made by compressed graphite components. Liang (2011) investigated a new filled-type tube collector using thermal transfer fluid as filled material. Study found that the thermal efficiency of the fill-type collector is $12 \%$ higher than that with copper fin. In this context, a liquid filled tube collector with double U-pipes is further investigated theoretically and experimentally in Liang (2012). The filled-type tube collector with double U-pipes has a 5\% efficiency improvement comparing with that with single U-pipe. Diaz (2008) developed mini-channel-based evacuated tube collector. Instead of U-pipe, the mini-channel with the same free flow is used to transfer heat to working fluid, with which the thermal efficiency can be improved 5\% approximately.

All the optimization methods mentioned above complicate the existing collector structure and therefore require more efforts in manufacturing. In this study, an optimization method is proposed to improve the heat transfer structure of evacuated tube collector with U-pipe. 
By adding a coating with high emissivity on the surface of aluminium fin, the radiation heat transfer coefficient between absorber tube and aluminium fin can increase from $2.0 \mathrm{~W} / \mathrm{m}^{2} \mathrm{~K}$ to $10.86 \mathrm{~W} / \mathrm{m}^{2} \mathrm{~K}$, which reduce the thermal resistance due to air gap efficiently. The thermal efficiency of collector with high emissivity coating on the aluminium surface can be $2.6 \%$ higher than that without optimization maximumly.

In this paper, the mathematical model is developed to analyse the thermal behaviour of U-pipe glass evacuated tube collector. The detailed fin model is put forward to investigate the temperature distribution along fin circular direction with consideration of effect of the temperature difference between two legs of U-pipe. The thermal model is further validated with experimental data from Gao (2014). Then, the thermal performances of collector with and without adding coating on fin surface under various operating conditions are simulated, and the coating temperature and the heat transfer coefficient between the absorber tube and the aluminium are analysed.

\section{Method}

The important parts of a single U-pipe glass evacuated tube collector is presented in Figure 1. The tube collector is mainly consisted of a two-layered glass tube, and the selective absorbing coating is mounted on the outer surface of the inter glass tube. A vacuum space is established between two glass layers. Thereby the heat loss is efficiently reduced due to the elimination of convective heat transfer. To enhance the thermal efficiency, the U-pipe is wedged inside a circular aluminium fin. During operation, the solar irradiance passes through the outer glass shell, and is absorbed by the selective absorbing coating. The converted thermal energy then heats the aluminium fin and U-pipe. The collected solar energy finally transfers into the working fluid and become useful heat gain.

One-dimensional model is used to investigate the thermal transfer process described above. To simplify calculation without losing acceptable accuracy, a set of assumptions has been made. (1) Only steady state performance of collector is analysed. Dynamic thermal behaviour is not involved in this study. (2) The solar energy absorbed by the outer glass tube is neglected. (3) The temperature gradient along the tube circumferential direction is neglected. (4) The thermal resistances caused by thickness of outer tube and inner glass tube are neglected, thus one single temperature of each tube layer is calculated in this model.

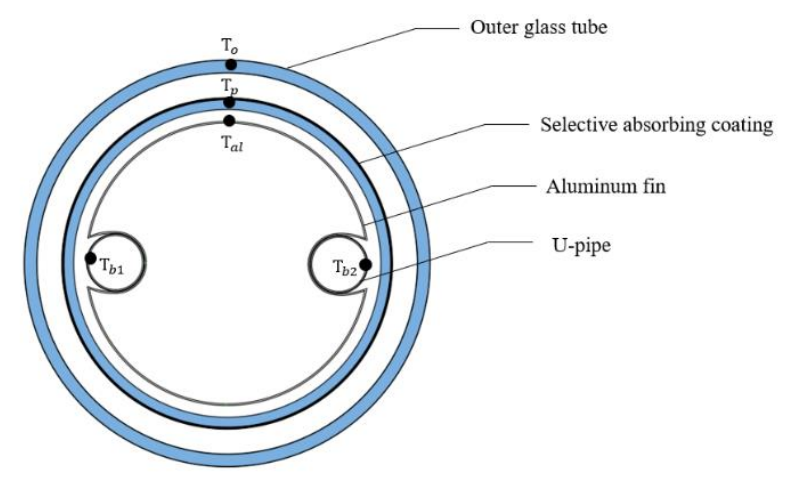

Figure 1: Cross section of a single tube. 


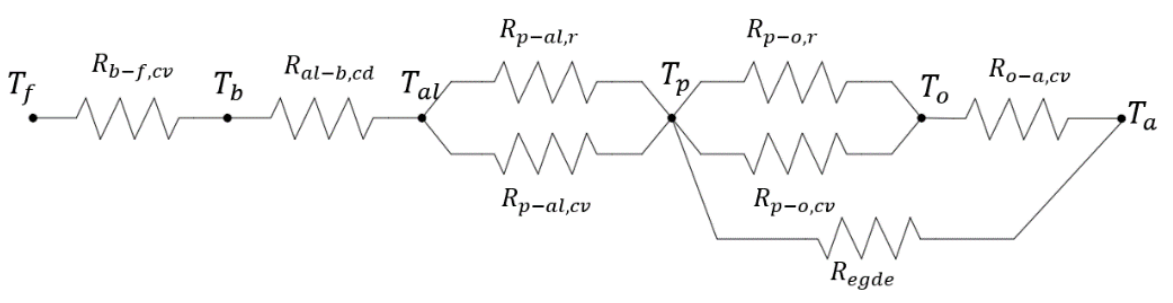

Figure 2: Thermal network of a single tube.

\section{Theoretical Model}

Based on above assumptions, the thermal network describing the heat transfer process is illustrated in Figure 2. The thermal model is composed of heat balance equations of each part and corresponding thermal transfer coefficients.

(1) outer glass tube

The heat balance equation of outer glass tube per unit collector length is illustrated as following.

$$
\mathrm{h}_{\mathrm{o}-\mathrm{a}, \mathrm{cv}} \mathrm{P}_{\mathrm{o}}\left(\mathrm{T}_{\mathrm{a}}-\mathrm{T}_{\mathrm{o}}\right)+\mathrm{h}_{\mathrm{p}-\mathrm{o}} \mathrm{P}_{\mathrm{p}}\left(\mathrm{T}_{\mathrm{p}}-\mathrm{T}_{\mathrm{o}}\right)=0
$$

Where $\mathrm{T}_{\mathrm{a}}, \mathrm{T}_{\mathrm{o}}$ and $\mathrm{T}_{\mathrm{p}}$ represent ambient air temperature, outer glass tube temperature and inner tube temperature respectively. $\mathrm{P}_{\mathrm{o}}$ and $\mathrm{P}_{\mathrm{p}}$ are the perimeters of the outer and inner glass tube. $\mathrm{h}_{\mathrm{o}-\mathrm{a}, \mathrm{cv}}$ is the convective heat transfer coefficient between outer tube and ambient environment, of which the value is related with wind velocity $w$ and can be calculated by empirical expression (2) (Duffie 1980).

$$
h_{o-a, c v}=\frac{\lambda_{a}}{D_{g}}\left(0.4+0.54\left(\frac{W D_{g}}{v_{a}}\right)^{0.52}\right)
$$

Where $\lambda_{a}, v_{a}$ are the thermal conductivity and viscosity of ambient air.

In expression (1), $h_{p-o}$ presents the heat transfer coefficient between two glass layers. Based on the thermal network, $h_{p-o}=h_{p-o, c v}+h_{p-o, r}$. As there exits vacuum space between outer and inner glass tube, the convective heat transfer coefficient $h_{p-o, c v}$ is considered to be $0 \mathrm{~W} /\left(\mathrm{m}^{2} \mathrm{~K}\right)$, and the radiation heat transfer between two glass layers $h_{p-o, r}$ is a function of tube surface temperatures, which can be expressed as

$$
h_{p-o, r}=\frac{\sigma \varepsilon_{p}}{1+\frac{\varepsilon_{p} D_{p}}{\varepsilon_{o} D_{o}}\left(1-\varepsilon_{p}\right)}\left(T_{p}{ }^{2}+T_{o}{ }^{2}\right)\left(T_{p}+T_{o}\right)
$$

Where $\varepsilon_{o}$ is the emissivity of the outer glass tube and has a value of 0.8 . The selective coating has low emissivity in long wave radiation range $\varepsilon_{p}$ of 0.02 . $\sigma$ represents StefanBoltzmann constant.

(2) absorber tube

$$
\begin{aligned}
h_{p-o} P_{p}\left(T_{o}-T_{p}\right)+ & h_{\text {edge }} P_{p}\left(T_{a}-T_{p}\right) \\
& +h_{p-a l} P_{p}\left(T_{a l}-T_{p}\right)+S=0
\end{aligned}
$$

Where $S$ represents the amount of solar energy absorbed by selective coating per tube length, which is a function of solar irradiance and can be estimated by expression (5).

$$
\mathrm{S}=\tau_{g} \alpha_{p} 1.43 D_{g} I_{o}
$$

Where $I_{o}$ is the total solar irradiation on the collector aperture surface, $\tau_{g}$ represents the optical transmission coefficient of outer glass tube and $\alpha_{p}$ is the absorption coefficient of the selective coating. Considering the effects of ground reflected radiation, diffuse radiation and the influence of different incident angle on optical transmittance, the effective aperture perimeter is assumed to be 1.43 times the diameter of absorbing tube $D_{g}$ (Yin 1996). Besides the thermal energy dissipating through outer glass shell, heat loss can also be caused by direct thermal conduction from absorber tube to atmosphere through the manifold connection at the head of collector. The edge heat loss coefficient $h_{\text {edge }}$ is difficult to be predicted as it relates to the collector insulation thickness and surface situation. Hence, an experimental value of $0.1687 \mathrm{~W} /\left(\mathrm{m}^{2} \mathrm{~K}\right)$ is used in this study (Tian 2007).

In expression (4), $h_{p-a l}$ represents the heat transfer coefficient between absorbing tube and aluminium fin. The heat transfer process is carried out by air conduction and radiation heat transfer and could be written as $h_{p-a l}=h_{p-a l, r}+h_{p-a l, c d}$, where

$$
\begin{gathered}
h_{p-a l, c d}=\frac{\lambda_{a}}{\delta_{a}} \\
h_{p-a l, r}=\frac{\sigma \varepsilon_{i}}{1+\frac{\varepsilon_{i} D_{p}}{\varepsilon_{a l} D_{a l}}\left(1-\varepsilon_{a l}\right)}\left(T_{p}{ }^{2}+T_{a l}{ }^{2}\right)\left(T_{p}+T_{a l}\right)
\end{gathered}
$$

$\delta_{a}$ is the thickness of air layer and $\lambda_{a}$ is the thermal conductivity. $\varepsilon_{i}$ represents the emissivity of inner surface of inner glass tube and has a value of $0.8 . h_{p-a l, c d}$ has a value of $26.7 \mathrm{~W} /\left(\mathrm{m}^{2} \mathrm{~K}\right)$ due to the thin air layer with a thickness of $1 \mathrm{~mm}$. Since the emissivity of aluminium fin is low $\left(\varepsilon_{a l}=0.2\right)$, the radiation heat transfer coefficient $h_{p-a l, r}$ is no more than $2.0 \mathrm{~W} /(\mathrm{m} 2 \mathrm{~K})$. This means that the air thermal conduction is dominant in this heat transfer process and the contribution of radiation is low. However, $h_{p-a l, r}$ could reach $10.9 \mathrm{~W} /\left(\mathrm{m}^{2} \mathrm{~K}\right)$ when the fin emissivity $\varepsilon_{a l}$ has a value of 0.95 , this could be realized by adding a high emissivity coating on the surface of aluminium fin.

(3) aluminium fin

As the circular aluminium fin connects with two legs of the U-pipe, the temperature of metal fin varies along the circumferential direction. To model the heat transfer process of the fin, Ma (2010) investigated the fin thermal transfer efficiency with the assumption that the heat transfer between two legs is symmetrical. Gao (2014) simplified the U-pipe as a single pipe and analysed the heat transfer process with equivalent fin model. Both methods neglect the effect of temperature difference between the inlet and outlet legs of the U-pipe. 


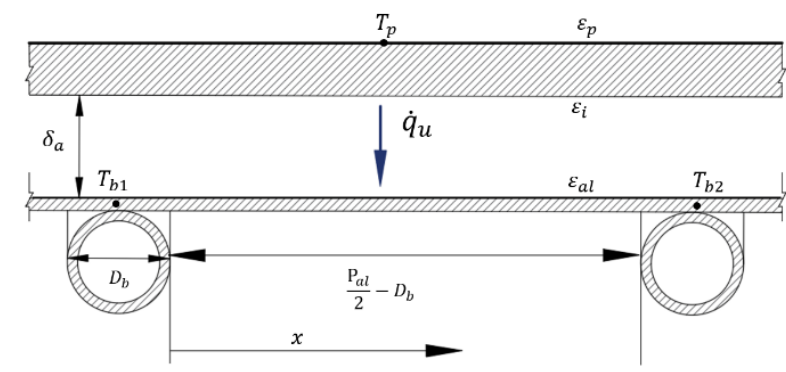

Figure 3: Heat transfer process on aluminium fin.

In this study, based on the first method, the corresponding boundary condition are redefined. The heat transfer process of the aluminium fin could be expressed as following.

$$
\lambda_{a l} \frac{d^{2} T_{a l}}{d x^{2}}+\frac{h_{p-a l}}{\delta_{a l}}\left(T_{p}-T_{a l}\right)=0
$$

Where $T_{a l}$ represents the temperature of aluminum fin. Two boundary conditions are necessary to solve this second-order differential equation.

$\left.T_{a l}\right|_{x=0}=T_{b 1}$ and $\left.T_{a l}\right|_{x=l}=T_{b 2}$

Where $l$ can be expressed as

$$
l=\frac{P_{a l}}{2}-d_{b}
$$

$T_{b 1}$ and $T_{b 2}$ represent the temperatures of inlet and outlet pipe respectively. The solution of equation (8) indicates the temperature distribution of aluminium fin in the $\mathrm{x}$ direction, which can be written as

$$
T_{a l}=T_{p}-\frac{\left(T_{p}-T_{b 1}\right) \sinh (m(l-x))+\left(T_{p}-T_{b 2}\right) \sinh (m x)}{\sinh (m l)}
$$

where $m$ is defined as

$$
\mathrm{m}=\left(\frac{h_{p-a l}}{\lambda_{a l} \delta_{a l}}\right)^{0.5}
$$

The thermal energy conducted to the inlet and outlet legs of U-pipe per tube length can be obtained by evaluating Fourier's law at the fin location $\mathrm{x}=0$ and $\mathrm{x}=1$.

$$
\begin{aligned}
& \dot{q}_{\left.f i n\right|_{x=l}}=m \lambda_{a l} \delta_{a l} \frac{\left[\left(T_{p}-T_{b 2}\right)-\left(T_{p}-T_{b 1}\right) \cosh (m l)\right]}{\sinh (m l)} \\
& \dot{q}_{\left.f i n\right|_{x=l}}=m \lambda_{a l} \delta_{a l} \frac{\left[\left(T_{p}-T_{b 1}\right)-\left(T_{p}-T_{b 2}\right) \cosh (m l)\right]}{\sinh (m l)}
\end{aligned}
$$

(4) U-pipe

The heat gain of U-pipe includes the conductive thermal energy form aluminium fin $\dot{q}_{\text {fin }}$ and energy collected above the tube region $\dot{q}_{t u b e}$. The energy balance equations of inlet and outlet pipes per collector length can be expressed separately as

$$
\begin{aligned}
& 2 \dot{q}_{\left.f i n\right|_{x=0}}+\dot{q}_{\left.t u b e\right|_{x=0}}+h_{f}\left(T_{f 1}-T_{b 1}\right) \pi D_{b}=0 \\
& 2 \dot{q}_{\left.f i n\right|_{x=l}}+\dot{q}_{\left.t u b e\right|_{x=l}}+h_{f}\left(T_{f 2}-T_{b 2}\right) \pi D_{b}=0
\end{aligned}
$$

Where $\dot{q}_{\left.t_{u b e}\right|_{x=0}}, \dot{q}_{\left.t_{u b e}\right|_{x=l}}$ can be defined in following expressions:

$$
\begin{aligned}
& \dot{q}_{\text {tube }\left.\right|_{x=0}}=h_{p-a l}\left(T_{p}-T_{b 1}\right) D_{b} \\
& \dot{q}_{\text {tube }_{x=l}}=h_{p-a l}\left(T_{p}-T_{b 2}\right) D_{b}
\end{aligned}
$$

In expression (14) (15), $T_{f 1}$ and $T_{f 2}$ are the average fluid temperatures at inlet and outlet legs of U-pipe. $h_{f}$ represents the convective heat transfer coefficient between working fluid and pipe inner surface, which can be calculated by empirical correlation expressed in following section.

(5) working fluid

Along the flow direction of working fluid, the heat transfer process at two sides of U-pipe can be described as

$$
\begin{gathered}
h_{f}\left(T_{b 1}-T_{f 1}\right) \pi D_{b} L_{u}+\dot{m} C_{p}\left(T_{f, \text { in }}-T_{f, \text { mid }}\right)=0 \\
h_{f}\left(T_{b 2}-T_{f 2}\right) \pi D_{b} L_{u}+\dot{m} C_{p}\left(T_{f, \text { mid }}-T_{f, \text { out }}\right)=0
\end{gathered}
$$

Where $L_{u}$ represents the length of U-pipe. And $T_{f, m i d}$ is the temperature of working fluid at the tube bend, which can be calculated by

$$
\begin{gathered}
T_{f, \text { mid }}=2 T_{f 1}-T_{f, \text { in }} \\
T_{f, \text { mid }}=2 T_{f, \text { out }}-T_{f 2}
\end{gathered}
$$

The convective heat transfer coefficient of fluid $h_{f}$ varies with fluid thermal properties, flow situation and wall surface temperature. In this study, the empirical correlations are used to predict the value (Oliver 1962).

$$
\begin{gathered}
h_{f}=\frac{\lambda_{f}}{D_{b}} N_{u} \\
N_{u}=1.75\left[G_{z}+5.6 \times 10^{-4}\left(G_{r} P_{r} \frac{L_{u}}{D_{b}}\right)^{0.70}\right]^{\frac{1}{3}}\left(\frac{v_{f}}{v_{\text {wall }}}\right)^{0.14}
\end{gathered}
$$

where $N_{u}$ is Nusselt number, $G_{z}$ is Graetz number, $P_{r}$ is Prandtl number, $G_{r}$ is Grashof number, $v_{f}$ and $v_{\text {wall }}$ are the viscosity of fluid at average fluid temperature and wall temperature.

Solar collector efficiency $\eta$ is used to evaluate the thermal performance of the glass evacuated tube collector. It is defined as the ratio between the net heat gain of working fluid and the solar radiation energy based on collector aperture area.

$$
\eta=\frac{m C_{p}\left(T_{f, \text { in }}-T_{f, \text { out }}\right)}{I_{o} A_{p}}
$$

where $A_{p}$ represents the aperture area.

Another important parameter to evaluate the collector thermal behaviour is the overall heat loss coefficient U_L, which is utilized to determine the thermal insulation standard of the glass evacuated tube collector. The overall loss coefficient between absorber tube and ambient environment U_L can be written as

$$
U_{L}=\frac{1}{\frac{1}{h_{o-a, c v}+h_{p-o, r}}+\frac{1}{h_{\text {edge }}}}
$$

\section{Model Validation}

To verify the reliability of this thermal model, the simulation result is compared with previous experimental data of Gao (2014). With boundary parameters, such as solar irradiance, ambient air temperature, flow rate and inlet water temperature using given values from referent experiment, the simulation results are compared with measurement data as well as simulated value from previous study. The predicted and experimental efficiency profiles are displayed in Figure 4. It is found that there is no huge difference between the predicted efficiency curve 
from present model and that from pervious study, and the simulation results match good with experimental data, which means the thermal model shows a good accuracy and can be utilized to predict the thermal performance of U-pipe evacuated tube collector. In addition, it is observed that the predicted thermal efficiency is slightly higher than experimental data, and the deviation increase with increasing temperature difference between working fluid and ambient air. The supposed reason is the uncertainty estimation of absorber area of solar irradiance. Considering the diffuse and ground reflected radiation, the empirical correlation from Yin (1998) is utilized in this study. Gao (2014) used the diameter of outer glass tube as equivalent aperture area. In addition, the edge loss coefficient in the thermal model is assumed to have an experimental value of $0.1687 \mathrm{~W} / \mathrm{m}^{2} \mathrm{~K}$, which could be higher in practice and leads to an underestimating of the overall heat loss to ambient environment.

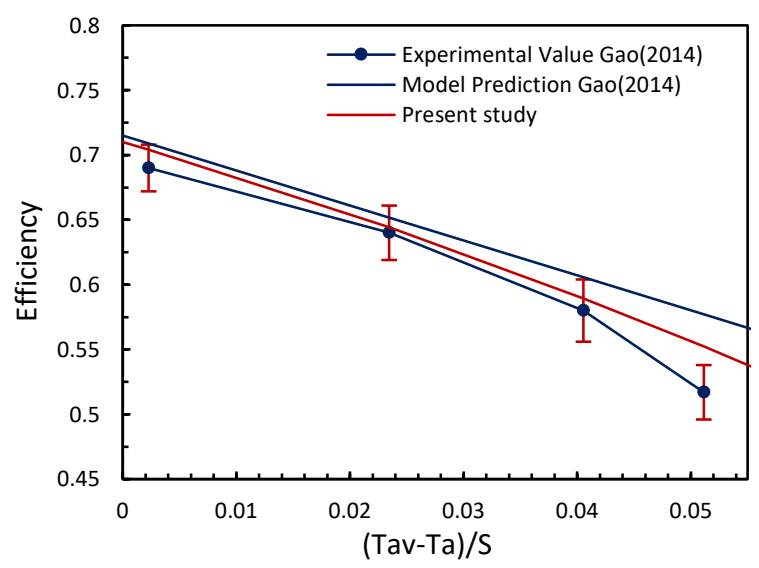

Figure 4: Steady state efficiency curve.

\section{Results and Discussion}

Under a given condition that the solar incidence on the aperture area is $950 \mathrm{~W} / \mathrm{m}^{2}$ and the ambient temperature is $10{ }^{\circ} \mathrm{C}$, the thermal behaviour of the U-pipe glass evacuated tube collectors with and without adding coating on fin surface is simulated. Figure 5 shows the thermal efficiency variation with temperature difference between working fluid temperature and atmosphere. As Figure 5 shows, the thermal efficiency of tube collector after optimization is $0.56 \%-1.35 \%$ higher than that of normal tube collector. The performance improvement is $0.56 \%$ at inlet temperature of $20{ }^{\circ} \mathrm{C}$, and increases up to $1.35 \%$ when the collector operates with an inlet temperature of $90{ }^{\circ} \mathrm{C}$, which indicates that the efficiency improvement is increscent with increasing inlet temperature, owing to a larger radiation heat transfer coefficient in high temperature application. In addition, the collector efficiency decreases with increasing temperature difference between working fluid and ambient, as the heat loss is higher with the increase of collector operating temperature. The collector performance maintains a value above $30 \%$ under a temperature difference of $70 \mathrm{~K}$, indicating that U-pipe glass tube collector have the ability to provide water with high temperature under extreme cold condition.

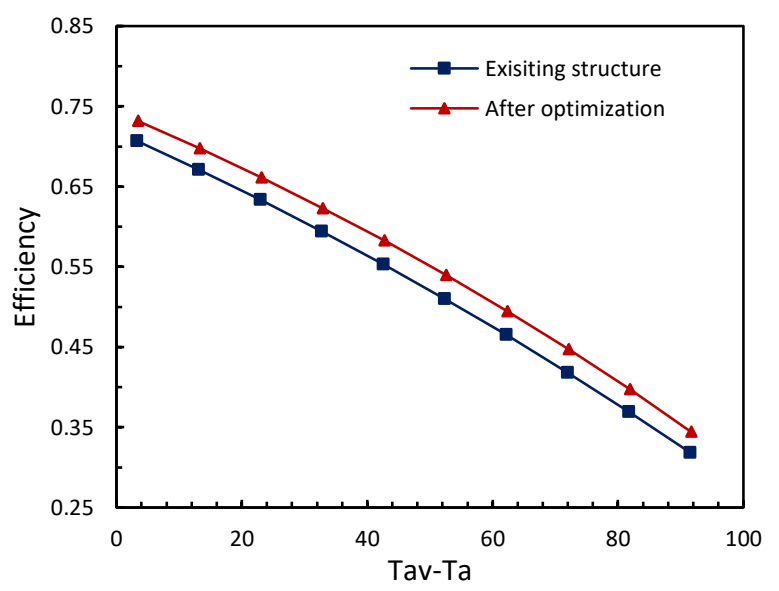

Figure 5: thermal efficiency variation with temperature difference.

Figure 6 gives the variation of heat transfer coefficient and coating temperature with temperature difference. It is observed that the coating temperature increases significantly with increasing inlet temperature and reaches a temperature of $115.2{ }^{\circ} \mathrm{C}$ maximumly. Coating temperature represents the highest temperature of collector, and an increase of whose value leads to a higher heat loss to ambient environment. The coating temperature can reduce 5.8-9.2 $\mathrm{K}$ with the optimization method. In addition, the heat transfer coefficient of normal collector represents as a constant value of 27 $\mathrm{W} /\left(\mathrm{m}^{2} \mathrm{~K}\right)$ approximately, compared with that, the heat transfer coefficient with a fin surface emissivity of 0.95 various from 32.0 to $39.5 \mathrm{~W} /\left(\mathrm{m}^{2} \mathrm{~K}\right)$ with the increase of coating temperature, indicating that the increase of fin surface emissivity improves the heat transfer process efficiently.

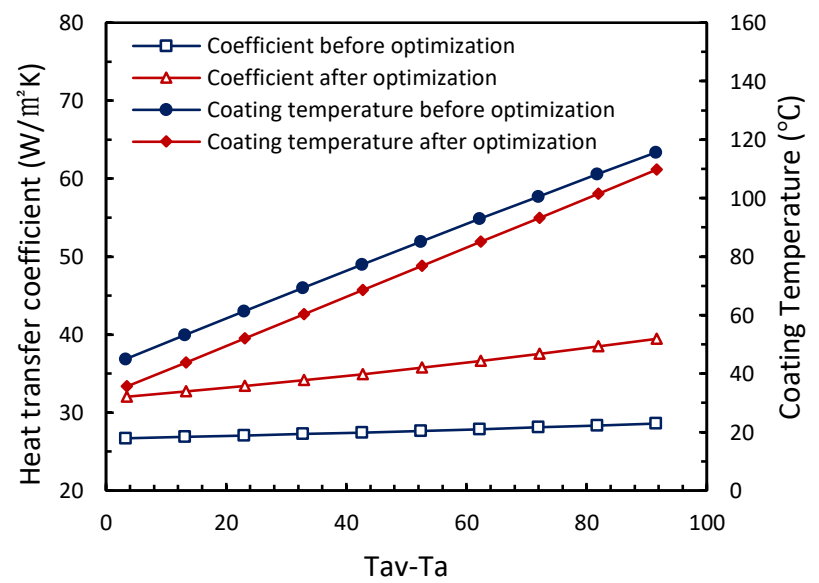

Figure 6: heat transfer coefficient and coating temperature variation with temperature difference.

Figure 7 shows the variation of the collector efficiency with solar radiation intensity under the condition of $10^{\circ} \mathrm{C}$ ambient temperature and $80^{\circ} \mathrm{C}$ inlet temperature. It is observed that the thermal efficiency increases dramatically with increase of solar radiation intensity. In addition, the performance improvement of collector with high emissivity fin coating increases from $0.1 \%$ to $2.6 \%$ 
as the radiation intensity ranges from $400 \mathrm{~W} / \mathrm{m}^{2}$ to 1200 $\mathrm{W} / \mathrm{m}^{2}$, and shows a continuous increasing tendency in higher radiation intensity range, indicating that the optimization method exhibits a better effect with increase of solar energy collected on absorbing area.

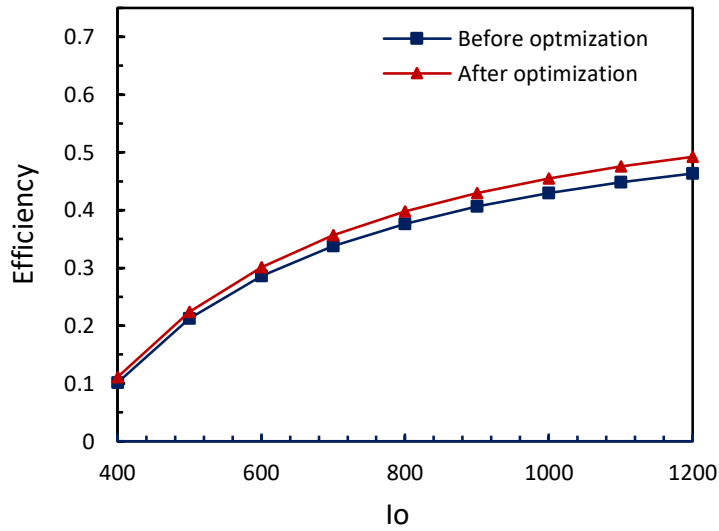

Figure 7: collector efficiency varies with radiation intensity.

\section{Nomenclature}

Symbols

$\mathrm{h}$ heat transfer coefficient $\left(\mathrm{W} / \mathrm{m}^{2} \mathrm{~K}\right)$

$\mathrm{P}$ the perimeter $(\mathrm{m})$

$\mathrm{R}$ thermal resistance per tube length (mK/W)

LL the length of tube $(\mathrm{m})$

D the diameter of tube (m)

S absorbed solar energy per tube length (W/m)

W wind velocity $(\mathrm{m} / \mathrm{s})$

$\mathrm{T}$ temperature $\left({ }^{\circ} \mathrm{C}\right)$

$I_{o} \quad$ solar radiation intensity $\left(\mathrm{W} / \mathrm{m}^{2}\right)$

$A_{p} \quad$ aperture area of collector $\left(\mathrm{m}^{2}\right)$

$C_{p} \quad$ specific heat capacity $\left(\mathrm{J} / \mathrm{kg}{ }^{\circ} \mathrm{C}\right)$

$N_{u} \quad$ Nusselt number

$P_{r} \quad$ Prandtl number

$G_{r} \quad$ Grashof number

$\dot{q} \quad$ specific heat flux per tube length (W/m)

$\varepsilon \quad$ emission coefficient

\section{References}

Diaz, G. (2008). Performance analysis and design optimization of a mini-channel evacuated-tube solar collector. Proceedings of IMECE2008: International Mechanical Engineering Congress and Exposition. Boston, Massachusetts (USA), 31 October - 6 November 2008.

Dirk, H., Walter, Z., Werner, G. (2008). Vacuum tubes for solar collectors with improved heat transfer. United States Patent Application 20080156314,

\section{Conclusion}

In this study, a one-dimensional numerical model of Upipe glass evacuated tube collector is built, and the heat transfer process of each collector part is investigated detailly. This theoretical model is further verified using previous experimental data from literature, and the computational results show in good agreement with existing measurement data. To reduce the thermal resistance caused by the air layer between absorbing tube and aluminium fin, an optimization method is proposed in this study. By deposing a coating with high emissivity on the fin surface, the radiation heat transfer coefficient can increase from 1.24 to $10.88 \mathrm{~W} /\left(\mathrm{m}^{2} \mathrm{~K}\right)$, which leads to a lower coating temperature and higher collector thermal efficiency. Further investigation on the optimization effect of this method are presented. Study find that the improvement of collector efficiency, which is contributed by adding a coating on fin surface, is strongly related with fluid inlet temperature and incident solar radiation. The simulation results indicate that the U-pipe glass evacuated tube collector with water as working fluid can have a maximum thermal efficiency increasement of $2.6 \%$ after optimization.

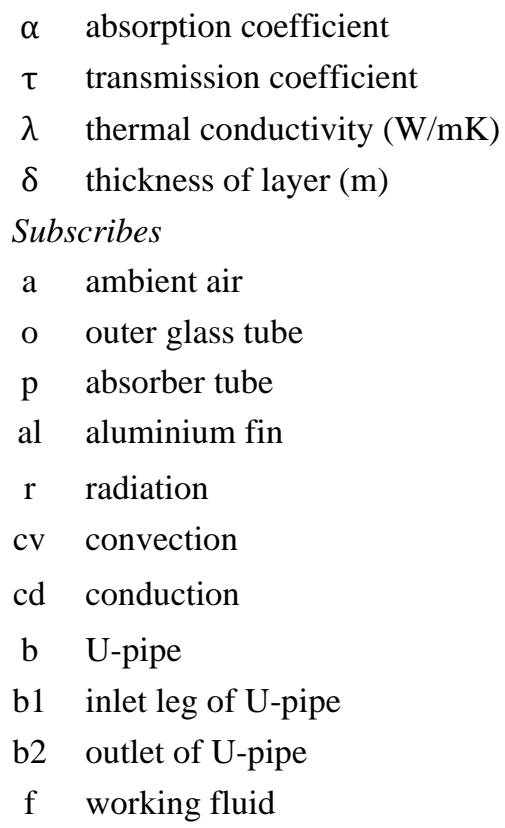

<http://www.freepatentsonline.com/y2008/0156314.html

Duffie, J.A., Beckman, W.A. (1980). Solar engineering of thermal processes. John Wiley \& Sons. New York (USA). Gao, Y., Fan, R., Zhang, X.Y., AN, Y.J., Wang, M.X., Gao, Y.K., Yu, Y. (2014). Thermal performance and parameter analysis of a U-pipe evacuated solar tube collector. Solar Energy 107, 714-727.

He, Z.N., Ge, H.C., Jiang, F.L., Li, W. (1997). A comparison of optical performance between evacuated 
collector tubes with flat and semi-cylindric absorbers. Solar Energy 60(2),109-117.

Kim, Y., and Seo, T. (2007). Thermal performances comparisons of the glass evacuated tube solar collectors with shapes of absorber tube. Renewable Energy 32(5), 772-795.

Liang, R.B., Ma, L.D., Zhang, J.I, Zhao, D. (2011). Theoretical and experimental investigation of the filledtype evacuated tube solar collector with U tube. Solar Energy 85 (9), 1735-1744.

Liang, R.B., Ma, L.D., Zhang, J.I, Zhao, L. (2013). Performance analysis of a new-design filled-type solar collector with double U-tubes. Energy and Buildings 57, 220-226.
Ma, L.D., Lu, Z., Zhang, J.I., Liang, R.B. (2010). Thermal performance analysis of the glass evacuated tube solar collector with U-tube. Building and Environment 45(9), 1959-1967.

Oliver, D.R. (1962). The effect of natural convection on viscous-flow heat transfer in horizontal tubes. Chemical Engineering Science 17(5), 335-350.

Tian, Q. (2007). Thermal performance of the U-type evacuated glass tubular solar collector. Building Energy \& Environment 26(3), 51-54 [in Chinese].

Yin, Z.Q. Yan, X.W., Chen, T.H., Zhao, T.S., An, R.H., Tang, X. (1996). Thermal properties of solar absorbing coatings and vacuum collectors. Acta Energiae Solaris Sinica 17(1), 50-56 [in Chinese]. 